\title{
Lysine: biosynthesis, catabolism and roles
}

Cody J. Hall ${ }^{1}$, Tatiana P. Soares da Costa ${ }^{1 *}$

\begin{abstract}
Amino acids are an essential building block of all life and are commonly incorporated into extending polypeptide chains to produce proteins. Lysine is one such amino acid and is classified as basic and positively charged at physiological $\mathrm{pH}$ due to the presence of an additional amino chemical group on the side chain. Lysine has two main biosynthetic pathways, namely the diaminopimelate and $\alpha$-aminoadipate pathways, which employ different enzymes and substrates and are found in different organisms. Lysine catabolism occurs through one of several pathways, the most common of which is the saccharopine pathway. Lysine plays several roles in humans, most importantly proteinogenesis, but also in the crosslinking of collagen polypeptides, uptake of essential mineral nutrients, and in the production of carnitine, which is key in fatty acid metabolism. Furthermore, lysine is often involved in histone modifications, and thus, impacts the epigenome. Due to the importance of lysine in several biological processes, a lack of lysine can lead to several disease states including; defective connective tissues, impaired fatty acid metabolism, anaemia, and systemic protein-energy deficiency. In juxtaposition to this, an overabundance of lysine, caused by ineffective catabolism, can cause severe neurological issues.
\end{abstract}

\section{Introduction}

Lysine (abbreviated as Lys or $\mathrm{K}$ ), is an $\alpha$-amino acid used for protein biosynthesis (proteinogenesis). There are many different kinds of amino acids, but only twenty are used universally by all forms of life for protein synthesis (i.e., proteogenic amino acids). The process of translation is how proteins are synthesised and lysine is added at the codons AAA and AAG. Lysine is an essential amino acid to all animals, including

${ }^{1}$ Department of Biochemistry and Genetics, La Trobe Institute for Molecular Science, La Trobe University, Bundoora, VIC 3086, Australia

*Author correspondence: T.SoaresdaCosta@latrobe.edu.au ORCID2: 0000-0002-6275-7485

Licensed under: CC-BY

Received 05-01-2018; accepted 01-06-2018

Keywords: Amino Acids, Lysine, Biosynthesis, Catabolism, Nutrition

\section{Plain language summary}

Proteins are key biomolecules found in all life and are composed of smaller structural units called amino acids. There are twenty amino acids found in all domains of life that are incorporated into proteins. These amino acids are composed of three key features, namely a carboxyl group (- $\mathrm{COOH})$, an amino group $\left(-\mathrm{NH}_{2}\right)$, and side chain ($\mathrm{R}$-group). One such amino acid, lysine, is classified as a basic and positively charged amino acid, due to the presence of an $-\mathrm{NH}_{3}{ }^{+}$located on the R-group. Lysine is considered essential in animals and, thus, must be obtained through dietary sources. Plants, bacteria, and fungi can biosynthesise their own lysine. There are two biosynthesis pathways that can generate lysine; the diaminopimelate and the $\alpha$-aminoadipate pathways. Whilst animals lack the biosynthesis machinery necessary to produce lysine, all organisms are capable of breaking down lysine into alternative biomolecules. The most common pathway for the breakdown of lysine is the saccharopine pathway that yields molecules used in the tricarboxylic acid cycle, which is a key carbon metabolic pathway found in all organisms. Lysine also plays several roles in human health and disease and, thus, an adequate amount of lysine must be obtained from the diet, which is commonly exceeded in western culture. Lysine has a primary role as a building block for proteins, however it also plays other key roles including in the structural protein, collagen, in calcium homeostasis, and in fatty acid metabolism. In addition to this, lysine plays an important role in epigenetics, as lysine is commonly the site of histone modification by addition or removal of a chemical or protein group. There are several disease states associated with either a lack or overabundance of lysine. There needs to be a delicate balance of all metabolites in living organisms and lysine is no exception, with a lack of lysine leading to symptoms such as anaemia, impaired fatty acid metabolism, and altered connective tissue properties as well as systemic affects due to protein-energy malnutrition. Conversely, the overabundance of lysine in plasma can be asymptomatic or lead to several debilitating neurological disorders, including psychomotor impairment, epilepsy, and ataxia. 
A

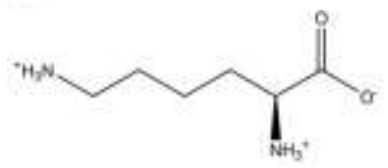

\section{B}

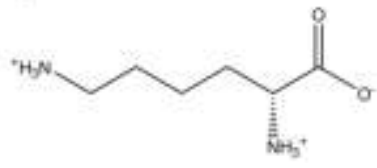

Figure 1 | Structure of lysine enantiomers at physiological $\mathrm{pH}$. Lysine can exist as one of two enantiomers, namely $(\mathrm{A}) L$ lysine and (B) $D$-lysine.

humans, and therefore must be obtained through dietary intake. ${ }^{[1][2]}$ Bacteria, archea, fungi, some protista (euglenids), and plants, on the other hand, are able to synthesise lysine. The organisms that are able to synthesise lysine can be thought of as the primary producers, on which all animals are dependent for their nutritional lysine requirement.

The free form of lysine kept at physiological $\mathrm{pH}$ contains a protonated $\alpha$-amino group $\left(-\mathrm{NH}_{3}{ }^{+}\right)$, a deproto-

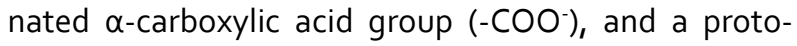
nated $\varepsilon$-amino side chain $\left(-\left(\mathrm{CH}_{2}\right)_{4} \mathrm{NH}_{3}{ }^{+}\right)$(Fig. 1$)$. Since its side can accept a proton at physiological $\mathrm{pH}$, lysine is classified as a basic amino acid akin to histidine and arginine. ${ }^{[3]}$ Lysine can exist as the $L$ - (left handed) (Fig. 1A) or $D$ - (right handed) (Fig. 1B) enantiomer due to its chiral $\alpha$-carbon atom, with the $L$-enantiomer being more abundant in nature. ${ }^{[4][3]}$ The reason for the greater abundance is that all living organisms selectively use the $L$-enantiomer form of all proteogenic amino acids for protein synthesis.

\section{Biosynthesis}

Two different pathways have been identified in nature for the synthesis of lysine. The diaminopimelate (DAP) pathway (Fig. 2A) belongs to the aspartate derived biosynthetic family, which is also involved in the synthesis of threonine, methionine and isoleucine. ${ }^{[5][6]}$ Whereas the $\alpha$-aminoadipate (AAA) pathway (Fig. 2B) is part of the glutamate biosynthetic family. ${ }^{[7][8]}$

The DAP pathway (Fig. 2A) is found in both prokaryotes and plants and begins with the dihydrodipicolinate synthase (DHDPS) (E.C 4.2.1.52) catalysed condensation reaction between the aspartate derived, $L$-aspartate semialdehyde, and pyruvate to form (4S)-4-hydroxy2,3,4,5-tetrahydro-(2S)-dipicolinic acid (HTPA) (Fig. 2A). ${ }^{[9][10][11][12][13]}$ The product is then reduced by dihydrodipicolinate reductase (DHDPR) (E.C 1.3.1.26), with $\mathrm{NAD}(\mathrm{P}) \mathrm{H}$ as a proton donor, to yield 2,3,4,5-tetrahydrodipicolinate (THDP) (Fig. 2A). ${ }^{[14]}$ From this point on, there are four pathway variations found in different

species, namely the acetylase, aminotransferase, dehydrogenase, and succinylase pathways. ${ }^{[5][15]}$ Both the acetylase and succinylase variant pathways use four enzyme catalysed steps, the aminotransferase pathway uses two enzymes, and the dehydrogenase pathway uses a single enzyme. ${ }^{[16]}$ These four variant pathways converge at the formation of the penultimate product, meso-diaminopimelate, which is subsequently enzymatically decarboxylated in an irreversible reaction catalysed by diaminopimelate decarboxylase (DAPDC) (E.C 4.1.1.20) to produce L-lysine (Fig. 2A). ${ }^{[17][18]}$ The DAP pathway is regulated at multiple levels, including upstream at the enzymes involved in aspartate processing as well as at the initial DHDPS catalysed condensation step. ${ }^{[18][19]}$ Lysine imparts a strong negative feedback loop on these enzymes and, subsequently, regulates the entire pathway. ${ }^{[19]}$

The AAA pathway (Fig. 2B) involves the condensation of $\alpha$-ketoglutarate and acetyl-CoA via the intermediate AAA for the synthesis of L-lysine. This pathway has been shown to be present in several yeast species, as well as protists and higher fungi. ${ }^{88][20][21][22][23][24][25]}$ It has also been reported that an alternative variant of the AAA route has been found in Thermus thermophilus and

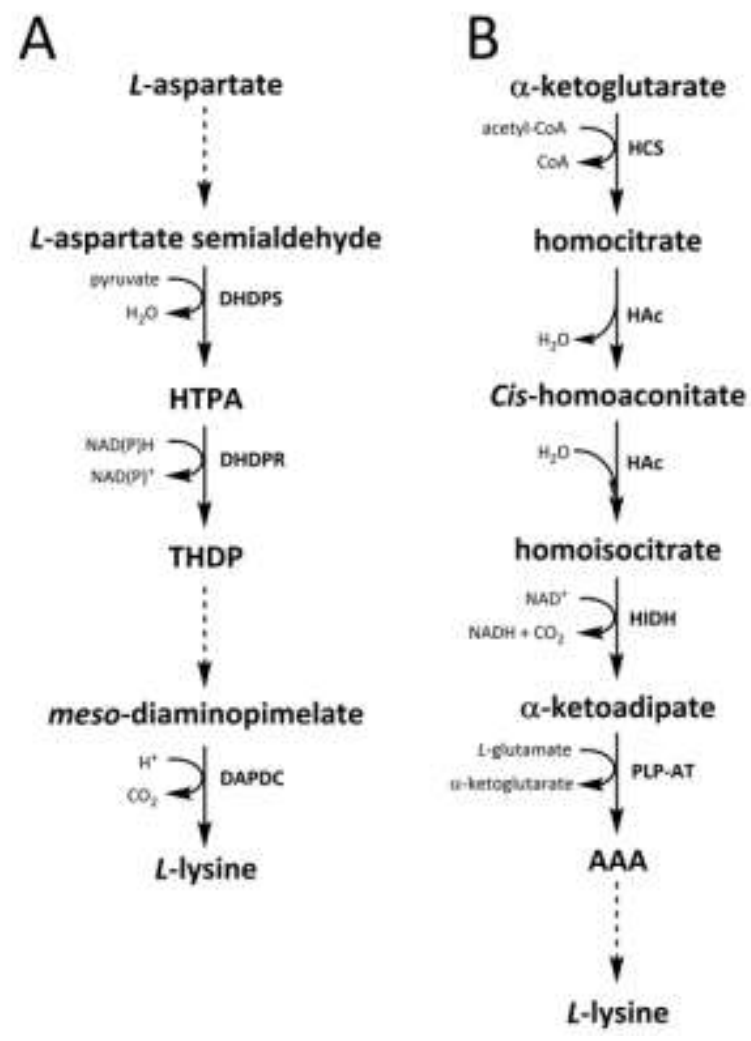

Figure 2 | Lysine biosynthesis pathways. Two pathways are responsible for the de novo biosynthesis of $L$-lysine, namely the (A) diaminopimelate pathway and (B) $\alpha$-aminoadipate pathway. 
Pyrococcus horikoshii, which could indicate that this pathway is more widely spread in prokaryotes than originally proposed. ${ }^{[26][27][28]}$ The first and rate-limiting step in the AAA pathway is the condensation reaction between acetyl-CoA and $\alpha$-ketoglutarate catalysed by homocitrate-synthase (HCS) (E.C 2.3.3.14) to give the intermediate homocitryl-CoA, which is hydrolysed by the same enzyme to produce homocitrate (Fig. 2B). ${ }^{[29]}$ Homocitrate is enzymatically dehydrated by homoaconitase (HAC) (E.C 4.2.1.36) to yield cis-homoaconitate ${ }^{[30]} \mathrm{HAc}$ then catalyses a second reaction in which cis-homoaconitate undergoes rehydration to produce homoisocitrate (Fig. 2B). ${ }^{[8]}$ The resulting product undergoes an oxidative decarboxylation by homoisocitrate dehydrogenase (HIDH) (E.C 1.1.1.87) to yield $\alpha$-ketoadipate. ${ }^{[8]} \mathrm{AAA}$ is then formed via a pyridoxal 5 '-phosphate (PLP)-dependent aminotransferase (PLP-AT) (E.C 2.6.1.39), using glutamate as the amino donor (Fig. 2B). ${ }^{[29]}$ From this point on, the AAA pathway differs depending on the kingdom. In fungi, AAA is reduced to $\alpha$-aminoadipate-semialdehyde via AAA reductase (E.C 1.2.1.95) in a unique process involving both adenylation and reduction that is activated by a phosphopantetheinyl transferase (E.C 2.7.8.7).$^{[8]}$ Once the semialdehyde is formed, saccharopine reductase (E.C 1.5.1.10) catalyses a condensation reaction with glutamate and $\mathrm{NAD}(\mathrm{P}) \mathrm{H}$, as a proton donor, and the imine is reduced to produce the penultimate product, saccharopine. ${ }^{[28]}$ The final step of the pathway in fungi involves the saccharopine dehydrogenase (SDH) (E.C 1.5.1.8) catalysed oxidative deamination of saccharopine, resulting in $L$ lysine. ${ }^{[8]}$ In a variant AAA pathway found in some prokaryotes, AAA is first converted to $N$-acetyl- $\alpha$-aminoadipate, which is phosphorylated and then reductively dephosphorylated to the $\varepsilon$-aldehyde. ${ }^{[28][29]}$ The aldehyde is then transaminated to $N$-acetyl-lysine, which is deacetylated to give $L$-lysine. ${ }^{[28][29]}$ However, the enzymes involved in this variant pathway need further validation.

\section{Catabolism}

Like all amino acids, catabolism of lysine is initiated from the uptake of dietary lysine or from the breakdown of intracellular protein. Catabolism is also used as a means to control the intracellular concentration of free lysine and maintain a steady-state to prevent the toxic effects of excessive free lysine. ${ }^{[1]}$ There are several pathways involved in lysine catabolism but the most commonly used is the saccharopine pathway (Fig. 3), which primarily takes place in the liver (and equivalent organs) in animals, specifically within the mitochondria. ${ }^{[2][3]][32][33]}$ Interestingly, this is the reverse of the previously described AAA pathway (Fig. 2B). ${ }^{[2][34]}$ In animals and plants, the first two steps of the saccharopine pathway are catalysed by the bifunctional enzyme, $\alpha$-aminoadipic semialdehyde synthase (AASS), which possess both lysine-ketoglutarate reductase (LKR) (E.C 1.5.1.8) and SDH activities, whereas in other organisms, such as bacteria and fungi, both of these enzymes are encoded by separate genes. ${ }^{[35][36]}$ The first step involves the LKR catalysed reduction of $L$-lysine in the presence of $\alpha$-ketoglutarate to produce saccharopine, with NAD (P)H acting as a proton donor (Fig. 3). ${ }^{[37]}$ Saccharopine then undergoes a dehydration reaction, catalysed by SDH in the presence of $\mathrm{NAD}^{+}$, to produce AAS and glutamate. ${ }^{[38]}$ AAS dehydrogenase (AASD) (E.C 1.2.1.31) then further dehydrates the molecule into AAA (Fig. 3). ${ }^{[37]}$ Subsequently, PLP-AT catalyses the reverse reaction to that of the AAA biosynthesis pathway, resulting in AAA being converted to $\alpha$-ketoadipate. The
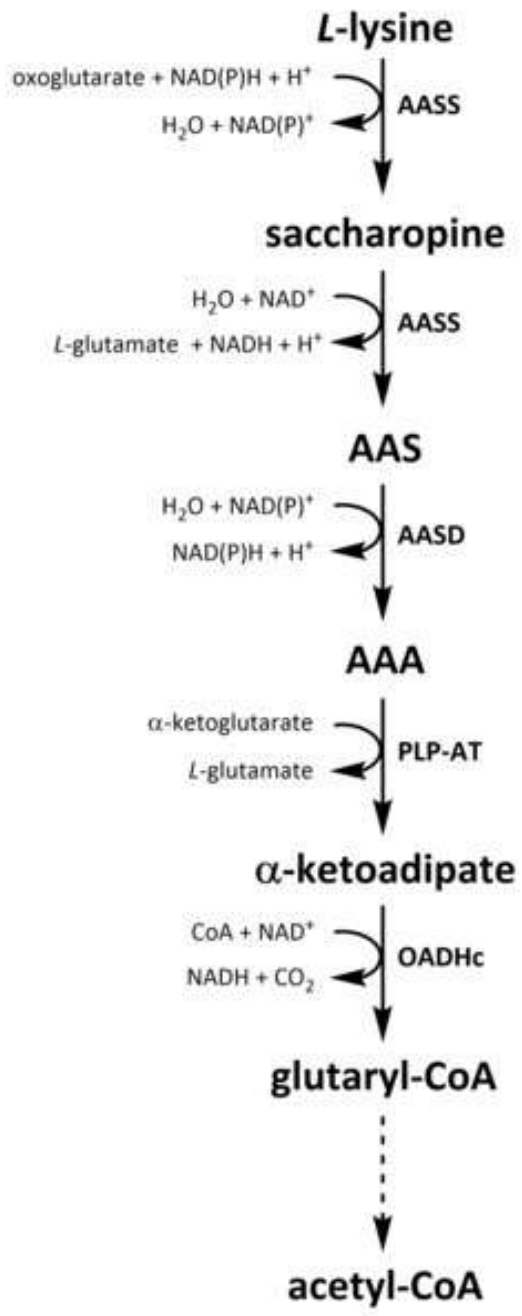

Figure 3 | Saccharopine lysine catabolism pathway. The saccharopine pathway is the most prominent pathway for the catabolism of lysine. 
product, $\alpha$-ketoadipate, is decarboxylated in the presence of $\mathrm{NAD}^{+}$and coenzyme $A$ to yeild glutaryl-CoA, however the enzyme involved in this is yet to be fully

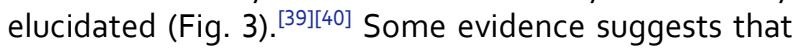
the 2-oxoadipate dehydrogenase complex $(\mathrm{OADHc})$, which is structurally homologous to the E1 subunit of the oxoglutarate dehydrogenase complex (OGDHc) (E.C 1.2.4.2), is responsible for the decarboxylation reaction. ${ }^{[39][41]}$ Finally, glutaryl-CoA is oxidatively decarboxylated to crotonyl-CoA by glutaryl-CoA dehydrogenase (E.C 1.3.8.6), which goes on to be further processed through multiple enzymatic steps to yield acetyl-CoA; an essential carbon metabolite involved in the tricarboxylic acid cycle (TCA). ${ }^{[37][42][43][44]}$

\section{Nutritional value}

Lysine is one of the nine essential amino acids in humans. ${ }^{[4]}$ The human nutritional requirements varies from $\sim 60 \mathrm{mg} \cdot \mathrm{kg}^{-1}$ in infancy to $\sim 30 \mathrm{mg} \cdot \mathrm{kg}^{-1}$ in adults. ${ }^{[2]}$ This requirement is commonly met in a western society with the intake of lysine from meat and vegetable sources well in excess of the recommended requirement. ${ }^{[2]}$ In vegetarian diets, the intake of lysine is less due to the limiting quantity of lysine in cereal crops compared to meat sources ${ }^{[2]}$ Given the limiting concentration of lysine in cereal crops, it has long been speculated that the content of lysine can be increased through genetic modification practices. ${ }^{[1][45]}$ Often these practices have involved the intentional dysregulation of the DAP pathway by means of introducing lysine feedback-insensitive orthologues of the DHDPS enzyme. ${ }^{[1][45]}$ These methods have met limited success likely due to the toxic side effects of increased free lysine and indirect effects on the TCA cycle. ${ }^{[46]}$ Plants accumulate lysine and other amino acids in the form of seed storage proteins, found within the seeds of the plant, and this represents the edible component of cereal crops. ${ }^{[47]}$ This highlights the need to not only increase free lysine, but also direct lysine towards the synthesis of stable seed storage proteins, and subsequently, increase the nutritional value of the consumable component of crops. ${ }^{[48][49]}$ Whilst genetic modification practices have met limited success, more traditional selective breeding techniques have allowed for the isolation of 'Quality Protein Maize', which has significantly increased levels of lysine (and tryptophan). This increase in lysine content is attributed to an opaque-2 mutation that reduced the transcription of lysine lacking zein related seed storage proteins and, as a result, increased the abundance of other proteins that are rich in lysine. ${ }^{[49][50]}$ Commonly, to overcome the limiting abundance of lysine in livestock feed, industrially produced lysine is added. ${ }^{[51][52]}$ The industrial process includes the fermentative culturing of Corynebacterium glutamicum and the subsequent purification of lysine. ${ }^{[51]}$

\section{Biological roles}

The most common role for lysine is proteinogenesis. Lysine frequently plays an important role in protein structure. Since its side chain contains a positively charged group on one end and a long hydrophobic carbon tail close to the backbone, lysine is considered somewhat amphipathic (Fig. 1). For this reason, lysine can be found buried as well as more commonly in solvent channels and on the exterior of proteins, where it can interact with the aqueous environment. ${ }^{[33]}$ Lysine can also contribute to protein stability as its $\varepsilon$-amino group often participates in hydrogen bonding, salt bridges and covalent interactions to form a Schiff base. ${ }^{[53][54][55][56]}$

A second major role of lysine is in epigenetic regulation by means of histone modification. ${ }^{[57][58]}$ There are several types of covalent histone modifications, which commonly involve lysine residues found in the protruding tail of histones. Modifications often include the addition or removal of an acetyl $\left(-\mathrm{CH}_{3} \mathrm{CO}\right)$, up to three methyl $\left(-\mathrm{CH}_{3}\right)$, ubiquitin or a sumo protein group. ${ }^{[5][59][60][61][62]}$ The various modifications have downstream effects on gene regulation, in which genes can be activated or repressed.

Lysine has also been implicated to play a key role in other biological processes including; structural proteins of connective tissues, calcium homeostasis, and fatty acid metabolism. ${ }^{[63][64][65]}$ Lysine has been shown to be involved in the crosslinking between the three helical polypeptides in collagen, resulting in its stability and tensile strength. ${ }^{[63][66]}$ This mechanism is akin to the role of lysine in bacterial cell walls, in which lysine (and meso-diaminopimelate) are critical to the formation of crosslinks, and therefore, stability of the cell wall. ${ }^{[67]}$ This concept has previously been explored as a means to circumvent the unwanted release of potentially pathogenic genetically modified bacteria. It was proposed that an auxotrophic strain of Escherichia coli $(x 1776)$ could be used for all genetic modification practices, as the strain is unable to survive without the supplementation of DAP, and thus, cannot live outside of a laboratory environment. ${ }^{[68]}$ Lysine has also been proposed to be involved in calcium intestinal absorption and renal retention, and thus, may play a role in calcium homeostasis. ${ }^{[64]}$ Finally, lysine has been shown to be a precursor for carnitine, which transports fatty acids to the mitochondria, where they can be oxidised for the release 
of energy. ${ }^{[65][69]}$ Carnitine is synthesised from trimethyllysine, which is a product of the degradation of certain proteins, as such lysine must first be incorporated into proteins and be methylated prior to being converted to carnitine. ${ }^{[65]}$ It must be noted however, that in mammals the primary source of carnitine is through dietary sources, rather than through lysine conversion. ${ }^{[65]}$

\section{Disputed roles}

There has been a long discussion that lysine, when administered intravenously or orally, can significantly increase the release of growth hormones. ${ }^{[70]}$ This has led to athletes using lysine as a means of promoting muscle growth while training, however, no significant evidence to support this application of lysine has been found to date. ${ }^{[70][71]}$ Another topic of discussion is the applicability of lysine as a treatment for the herpes simplex virus (HSV) due to a correlation between high levels of lysine and decreased symptoms and healing time of infected individuals. ${ }^{[72][73]}$ This claim has long been disputed, with studies concluding that lysine has no efficacy as a prophylactic or in the treatment of HSV. ${ }^{[74][75][76]}$

\section{Roles in disease}

Diseases related to lysine are a result of the downstream processing of lysine, i.e. the incorporation into proteins or modification into alternative biomolecules. The role of lysine in collagen has been outlined above, however, a lack of lysine and hydroxylysine involved in the crosslinking of collagen peptides has been linked to a disease state of the connective tissue. ${ }^{[7]}$ As carnitine is a key lysine-derived metabolite involved in fatty acid metabolism, a substandard diet lacking sufficient carnitine and lysine can lead to decreased carnitine levels, which can have significant cascading effects on an individual's health. ${ }^{[69][78]}$ Lysine has also been shown to play a role in anaemia, as lysine is suspected to have an effect on the uptake of iron and, subsequently, the concentration of ferritin in blood plasma. ${ }^{[79]}$ However, the exact mechanism of action is yet to be elucidated. ${ }^{[79]}$ Most commonly, lysine deficiency is seen in non-western societies and manifests as protein-energy malnutrition, which has profound and systemic effects on the health of the individual. ${ }^{[80][81]}$ There is also a hereditary genetic disease that involves mutations in the enzymes responsible for lysine catabolism, namely the bifunctional AASS enzyme of the saccharopine pathway (Fig. 3). ${ }^{\left[{ }^{[2]}\right.}$ Due to a lack of lysine catabolism, the amino acid accumulates in plasma and patients develop hyperlysinaemia, which can present as asymptomatic to severe neurological disabilities, including epilepsy, ataxia, spasticity, and psychomotor impairment. ${ }^{[82][83]}$ It must be noted however, that the clinical significance of hyperlysinemia is the subject of debate in the field with some studies finding no correlation between physical or mental disabilities and hyperlysinemia. ${ }^{[84]}$ In addition to this, mutations in genes related to lysine metabolism have been implicated in several disease states, including pyridoxine-dependent epilepsia (ALDH7A1 gene), $\alpha$-ketoadipic and $\alpha$-aminoadipic aciduria (DHTKD1 gene), and glutaric aciduria type 1 (GCDH gene). ${ }^{[39][85][86][87][88]}$

\section{Concluding remarks}

Lysine is a basic positively charged amino acid involved in several biological processes, including proteinogenesis, epigenetic regulation, crosslinking, mineral uptake, and metabolite production. Lysine is an essential amino acid as it cannot be synthesised de novo in animals and must be obtained through dietary intake of organisms that possess the biosynthetic pathways. Organisms that are capable of synthesising lysine do so using one of two major pathways, namely the DAP or the AAA pathway. The catabolism of lysine can vary significantly with several pathways involved in the breakdown of lysine into different metabolites. The most commonly used catabolic pathway is the saccharopine pathway, which results in the breakdown of lysine into the essential precursor involved in carbon flux, glutaryl-CoA. Lysine deficiency, arising from an inadequate diet, can lead to several disease states, thus highlighting the need for a balanced diet with sufficient intake of essential amino acids. In contrast to this, an excessive concentration of free lysine, due to stunted catabolism, can cause various neurological disorders. It must be noted that in highly complex organisms, such as humans, metabolites including lysine can be implicated in many different processes and this review has addressed some of these roles.

\section{Acknowledgements}

T.P.S.C. acknowledges the National Health and Medical Research Council of Australia for fellowship support (APP1091976) and C.J.H. acknowledges La Trobe University for scholarship support.

\section{References}

1. Galili, Gad; Amir, Rachel. "Fortifying plants with the essential amino acids lysine and methionine to improve nutritional quality". Plant Biotechnology Journal 11 (2): 211-222. doi:10.1111/pbi.12025.

2. Tomé, Daniel; Bos, Cécile (June 2007). "Lysine requirement through the human life cycle". The Journal of Nutrition 137 (6 Suppl 2): 1642S-1645S. ISSN 0022-3166. PMID 17513440. 
3. Gary., Walsh, (2014). Proteins : Biochemistry and Biotechnology. (2nd ed ed.). Hoboken: Wiley. ISBN 9781118851494. OCLC 873141049.

4. 1942-, Nelson, David L. (David Lee), (2013). Lehninger principles of biochemistry. Cox, Michael M.,, Lehninger, Albert L. (6th ed ed.). New York: W.H. Freeman and Company. ISBN 9781464109621. OCLC 824794893.

5. Hudson, Andre' O.; Bless, Christine; Macedo, Polliana; Chatterjee, Siba P.; Singh, Bijay K.; Gilvarg, Charles; Leustek, Thomas. "Biosynthesis of lysine in plants: evidence for a variant of the known bacterial pathways". Biochimica et Biophysica Acta (BBA) - General Subjects 1721 (1-3): 27-36. doi:10.1016/j.bbagen.2004.09.008.

6. Velasco, A. M.; Leguina, J. I.; Lazcano, A. (2002-10-01). "Molecular Evolution of the Lysine Biosynthetic Pathways". Journal of Molecular Evolution 55 (4): 445-449. doi:10.1007/s00239-002-2340-2. ISSN 00222844

7. Miyazaki, Takashi; Miyazaki, Junichi; Yamane, Hisakazu; Nishiyama, Makoto (2004). " $\alpha$-Aminoadipate aminotransferase from an extremely thermophilic bacterium, Thermus thermophilus". Microbiology 150 (7): 2327-2334. doi:10.1099/mic.0.27037-0.

8. Xu, Hengyu; Andi, Babak; Qian, Jinghua; West, Ann H.; Cook, Paul F. (2006-09-01). "The $\alpha$-aminoadipate pathway for lysine biosynthesis in fungi". Cell Biochemistry and Biophysics 46 (1): 43-64. doi:10.1385/cbb:46:1:43. ISSN 1085-9195.

9. Atkinson, Sarah C.; Dogovski, Con; Downton, Matthew T.; Czabotar, Peter E.; Dobson, Renwick C. J.; Gerrard, Juliet A.; Wagner, John; Perugini, Matthew A. (2013-03-01). "Structural, kinetic and computational investigation of Vitis vinifera DHDPS reveals new insight into the mechanism of lysine-mediated allosteric inhibition". Plant Molecular Biology 81 (4-5): 431-446. doi:10.1007/s11103-013-0014-7. ISSN 01674412.

10. Griffin, Michael D. W.; Billakanti, Jagan M.; Wason, Akshita; Keller, Sabrina; Mertens, Haydyn D. T.; Atkinson, Sarah C.; Dobson, Renwick C. J.; Perugini, Matthew A. et al. (2012-07-05). "Characterisation of the First Enzymes Committed to Lysine Biosynthesis in Arabidopsis thaliana". PLOS ONE 7 (7): e40318. doi:10.1371/journal.pone.0040318. ISSN 19326203.

11. Soares da Costa, Tatiana P.; Muscroft-Taylor, Andrew C.; Dobson, Renwick C.J.; Devenish, Sean R.A.; Jameson, Geoffrey B.; Gerrard, Juliet A.. "How essential is the 'essential' active-site lysine in dihydrodipicolinate synthase?". Biochimie 92 (7): 837-845. doi:10.1016/j.biochi.2010.03.004.

12. Soares da Costa, Tatiana P.; Christensen, Janni B.; Desbois, Sebastien; Gordon, Shane E.; Gupta, Ruchi; Hogan, Campbell J.; Nelson, Tao G.; Downton, Matthew T. et al.. Quaternary Structure Analyses of an Essential Oligomeric Enzyme. pp. 205-223. doi:10.1016/bs.mie.2015.06.020.

13. Muscroft-Taylor, Andrew C.; Costa, Tatiana P. Soares da; Gerrard, Juliet A.. "New insights into the mechanism of dihydrodipicolinate synthase using isothermal titration calorimetry". Biochimie 92 (3): 254-262. doi:10.1016/j.biochi.2009.12.004.

14. Christensen, Janni B. Costa, T. P. Soares da; Faou, Pierre; Pearce, F. Grant; Panjikar, Santosh; Perugini, Matthew A. (2016-11-15). "Structure and Function of Cyanobacterial DHDPS and DHDPR". Scientific Reports 6 (1). doi:10.1038/srep37111. ISSN 2045-2322.

15. McCoy, Andrea J.; Adams, Nancy E.; Hudson, André O.; Gilvarg, Charles; Leustek, Thomas; Maurelli, Anthony T. (2006-11-21). "I,I-diaminopimelate aminotransferase, a trans-kingdom enzyme shared by Chlamydia and plants for synthesis of diaminopimelate/lysine". Proceedings of the National Academy of Sciences 103 (47): 17909-17914. doi:10.1073/pnas.0608643103.

16. Hudson, André O.; Gilvarg, Charles; Leustek, Thomas (2008-05-01). "Biochemical and Phylogenetic Characterization of a Novel Diaminopimelate Biosynthesis Pathway in Prokaryotes Identifies a Diverged Form of II-Diaminopimelate Aminotransferase". Journal of Bacteriology 190 (9): 3256-3263. doi:10.1128/jb.01381-07. ISSN 00219193. PMID 18310350

17. Peverelli, Martin G.; Perugini, Matthew A.. "An optimized coupled assay for quantifying diaminopimelate decarboxylase activity". Biochimie 115: 78-85. doi:10.1016/j.biochi.2015.05.004

18. Soares da Costa, Tatiana P.; Costa, Tatiana P. Soares da; Desbois, Sebastien; Dogovski, Con; Gorman, Michael A.; Ketaren, Natalia E.; Paxman, Jason J.; Siddiqui, Tanzeela et al.. "Structural Determinants Defining the Allosteric Inhibition of an Essential Antibiotic Target". Structure 24 (8): 1282-1291. doi:10.1016/j.str.2016.05.019.

19. Jander, Georg; Joshi, Vijay (2009-01-01). "Aspartate-Derived Amino Acid Biosynthesis in Arabidopsis thaliana". The Arabidopsis Book: e0121. doi:10.1199/tab.0121.

20. Andi, Babak; West, Ann H.; Cook, Paul F. (2004-09-01). "Kinetic Mechanism of Histidine-Tagged Homocitrate Synthase from
Saccharomyces cerevisiae". Biochemistry 43 (37): 11790-11795. doi:10.1021/bi048766p. ISSN 0006-2960.

21. Bhattacharjee, J. K. (1985). "alpha-Aminoadipate pathway for the biosynthesis of lysine in lower eukaryotes". Critical Reviews in Microbiology 12 (2): 131-151. doi:10.3109/10408418509104427. ISSN 1040-841X. PMID 3928261.

22. Bhattacharjee, J. K.; Strassman, M. (1967-05-25). "Accumulation of tricarboxylic acids related to lysine biosynthesis in a yeast mutant". The Journal of Biological Chemistry 242 (10): 2542-2546. ISSN 0021-9258. PMID 6026248.

23. GAILLARDIN, Claude M.; RIBET, Anne-Marie; HESLOT, Henri. "Wild-Type and Mutant Forms of Homoisocitric Dehydrogenase in the Yeast Saccharomycopsis lipolytica". European Journal of Biochemistry 128 (2-3): 489-494. doi:10.1111/j.1432-1033.1982.tb06991.x.

24. Jaklitsch, W. M.; Kubicek, C. P. (1990-07-01). "Homocitrate synthase from Penicillium chrysogenum. Localization, purification of the cytosolic isoenzyme, and sensitivity to lysine". The Biochemical Journal 269 (1): 247253. ISSN 0264-6021. PMID 2115771. PMC PMC1131560.

25. Ye, Z. H.; Bhattacharjee, J. K. (1988-12-01). "Lysine biosynthesis pathway and biochemical blocks of lysine auxotrophs of Schizosaccharomyces pombe.". Journal of Bacteriology170 (12): 5968-5970. doi:10.1128/jb.170.12.5968-5970.1988. ISSN 0021-9193. PMID 3142867.

26. Kobashi, N.; Nishiyama, M.; Tanokura, M. (March 1999). "Aspartate kinase-independent lysine synthesis in an extremely thermophilic bacterium, Thermus thermophilus: lysine is synthesized via alphaaminoadipic acid not via diaminopimelic acid". Journal of Bacteriology 181 (6): 1713-1718. ISSN 0021-9193. PMID 10074061.

27. Kosuge, T.; Hoshino, T. (1999). "The alpha-aminoadipate pathway for lysine biosynthesis is widely distributed among Thermus strains". Journal of Bioscience and Bioengineering 88(6): 672-675. ISSN 1389-1723. PMID 16232683.

28. Nishida, H.. "A Prokaryotic Gene Cluster Involved in Synthesis of Lysine through the Amino Adipate Pathway: A Key to the Evolution of Amino Acid Biosynthesis". Genome Research 9 (12): 1175-1183. doi:10.1101/gr.9.12.1175.

29. Nishida, H.; Nishiyama, M. (September 2000). "What is characteristic of fungal lysine synthesis through the alpha-aminoadipate pathway?". Journal of Molecular Evolution 51 (3): 299-302. ISSN 0022-2844. PMID 11029074.

30. Zabriskie, T. Mark; Jackson, Michael D. (2000-01-01). "Lysine biosynthesis and metabolism in fungi". Natural Product Reports 17 (1): 85-97. doi:10.1039/a801345d. ISSN 1460-4752.

31. Zhu, Xiaohong; Galili, Gad (2004-05-01). "Lysine Metabolism Is Concurrently Regulated by Synthesis and Catabolism in Both Reproductive and Vegetative Tissues". Plant Physiology 135 (1): 129-136. doi:10.1104/pp.103.037168. ISSN 0032-0889. PMID 15122025.

32. Blemings, K. P.; Crenshaw, T. D.; Swick, R. W.; Benevenga, N. J. (August 1994). "Lysine-alpha-ketoglutarate reductase and saccharopine dehydrogenase are located only in the mitochondrial matrix in rat liver". The Journal of Nutrition 124 (8): 1215-1221. ISSN 0022-3166. PMID 8064371.

33. Galili, Gad; Tang, Guiliang; Zhu, Xiaohong; Gakiere, Bertrand. "Lysine catabolism: a stress and development super-regulated metabolic pathway". Current Opinion in Plant Biology 4(3): 261-266. doi:10.1016/s1369-5266(00)00170-9.

34. Arruda, Paulo; Kemper, Edson Li Papes, Fabio; Leite, Adilson. "Regulation of lysine catabolism in higher plants". Trends in Plant Science 5 (8): 324330. doi:10.1016/s1360-1385(00)01688-5.

35. Sacksteder, Katherine A.; Biery, Barbara J.; Morrell, James C.; Goodman, Barbara K.; Geisbrecht, Brian V.; Cox, Rody P.; Gould, Stephen J.; Geraghty, Michael T.. "Identification of the $\alpha$-Aminoadipic Semialdehyde Synthase Gene, Which Is Defective in Familial Hyperlysinemia". The American Journal of Human Genetics 66 (6): 1736-1743. doi:10.1086/302919.

36. Zhu, Xiaohong; Tang, Guiliang; Galili, Gad (2002-12-20). "The Activity of the Arabidopsis Bifunctional Lysine-ketoglutarate Reductase/Saccharopine Dehydrogenase Enzyme of Lysine Catabolism Is Regulated by Functional Interaction between Its Two Enzyme Domains". Journal of Biological Chemistry 277 (51): 49655-49661. doi:10.1074/jbc.m205466200. ISSN 0021-9258. PMID 12393892.

37. Kiyota, Eduardo; Pena, Izabella Agostinho; Arruda, Paulo (November 2015). "The saccharopine pathway in seed development and stress response of maize". Plant, Cell \& Environment 38 (11): 2450-2461. doi:10.1111/pce.12563. ISSN 1365-3040. PMID 25929294.

38. Serrano, Guilherme Coutinho de Mello; Rezende e Silva Figueira, Thaís; Kiyota, Eduardo; Zanata, Natalia; Arruda, Paulo (2012-03-23). "Lysine degradation through the saccharopine pathway in bacteria: LKR and SDH 
in bacteria and its relationship to the plant and animal enzymes". FEBS letters 586 (6): 905-911. doi:10.1016/j.febslet.2012.02.023. ISSN 18733468. PMID 22449979.

39. Danhauser, Katharina; Sauer, Sven W.; Haack, Tobias B.; Wieland, Thomas; Staufner, Christian; Graf, Elisabeth; Zschocke, Johannes; Strom, Tim M. et al.. "DHTKD1 Mutations Cause 2-Aminoadipic and 2-Oxoadipic Aciduria". The American Journal of Human Genetics 91 (6): 1082-1087. doi:10.1016/j.ajhg.2012.10.006

40. Saver, Sven W.; Opp, Silvana; Hoffmann, Georg F.; Koeller, David M.; Okun, Jürgen G.; Kölker, Stefan (2011-01-01). "Therapeutic modulation of cerebral I-lysine metabolism in a mouse model for glutaric aciduria type I". Brain 134 (1): 157-170. doi:10.1093/brain/awq269. ISSN 0006-8950.

41. Goncalves, Renata L.S.; Bunik, Victoria I.; Brand, Martin D.. "Production of superoxide/hydrogen peroxide by the mitochondrial 2-oxoadipate dehydrogenase complex". Free Radical Biology and Medicine 91: 247-255. doi:10.1016/j.freeradbiomed.2015.12.020.

42. Goh, Denise L.M; Patel, Ankita; Thomas, George $H_{;}$Salomons, Gajja S; Schor, Danielle S.M; Jakobs, Cornelis; Geraghty, Michael T. "Characterization of the human gene encoding $\alpha$-aminoadipate aminotransferase (AADAT)". Molecular Genetics and Metabolism 76 (3): 172-180. doi:10.1016/s1096-7192(02)00037-9.

43. Härtel, Ulrich; Eckel, Elke; Koch, Jürgen; Fuchs, Georg; Linder, Dietmar; Buckel, Wolfgang (1993-02-01). "Purification of glutaryl-CoA dehydrogenase from Pseudomonas sp., an enzyme involved in the anaerobic degradation of benzoate". Archives of Microbiology 159 (2): 174181. doi:10.1007/bf00250279. ISSN 0302-8933.

44. Saver, S. W. (October 2007). "Biochemistry and bioenergetics of glutarylCoA dehydrogenase deficiency". Journal of Inherited Metabolic Disease 30 (5): 673-680. doi:10.1007/s10545-007-0678-8. ISSN 1573-2665. PMID 17879145 .

45. Wang, Guoping; Xu, Mengyun; Wang, Wenyi; Galili, Gad (2017-06-19). "Fortifying Horticultural Crops with Essential Amino Acids: A Review". International Journal of Molecular Sciences 18 (6): 1306. doi:10.3390/ijms18061306.

46. Angelovici, Ruthie; Fait, Aaron; Fernie, Alisdair R.; Galili, Gad (January 2011). "A seed high-lysine trait is negatively associated with the TCA cycle and slows down Arabidopsis seed germination". The New Phytologist 189 (1): 148-159. doi:10.1111/j.1469-8137.2010.03478.x. ISSN 1469-8137. PMID 20946418.

47. Edelman, Marvin; Colt, Monica (2016). "Nutrient Value of Leaf vs. Seed". Frontiers in Chemistry 4. doi:10.3389/fchem.2016.00032. ISSN 2296-2646.

48. Jiang, Shu-Ye; Ma, Ali; Xie, Lifen; Ramachandran, Srinivasan (2016-09-28). "Improving protein content and quality by over-expressing artificially synthetic fusion proteins with high lysine and threonine constituent in rice plants". Scientific Reports 6 (1). doi:10.1038/srep34427. ISSN 2045-2322.

49. Shewry, Peter R.. "Improving the protein content and composition of cereal grain". Journal of Cereal Science 46 (3): 239-250. doi:10.1016/j.jcs.2007.06.006.

50. Prasanna, B. M.; Vasal, S. K.; Kassahun, B.; Singh, N. N. (2001). "Quality protein maize". Current Science 81 (10): 1308-1319.

51. Kircher, Manfred; Pfefferle, Walter. "The fermentative production of Ilysine as an animal feed additive". Chemosphere 43 (1): 27-31. doi:10.1016/s0045-6535(00)00320-9.

52. Junior, Letti; Alberto, Luiz; Letti, Gilberto Vinícius Melo; Soccol, Carlos Ricardo; Junior, Letti; Alberto, Luiz; Letti, Gilberto Vinícius Melo; Soccol, Carlos Ricardo (00/2016). "Development of an L-Lysine Enriched Bran for Animal Nutrition via Submerged Fermentation by Corynebacterium glutamicum using Agroindustrial Substrates". Brazilian Archives of Biology and Technology 59. doi:10.1590/1678-4324-2016150519. ISSN 1516-8913.

53. Betts, Matthew J.; Russell, Robert B. (2003). Barnes, Michael R.. ed. Bioinformatics for Geneticists. John Wiley \& Sons, Ltd. pp. 289-316. doi:10.1002/0470867302.ch14/summary. ISBN 9780470867303.

54. Blickling, S.; Renner, C.; Laber, B.; Pohlenz, H. D.; Holak, T. A.; Huber, R. (1997-01-07). "Reaction mechanism of Escherichia coli dihydrodipicolinate synthase investigated by X-ray crystallography and NMR spectroscopy". Biochemistry 36 (1): 24-33. doi:10.1021/bi962272d. ISSN 0006-2960. PMID 8993314.

55. Kumar, Sandeep; Tsai, Chung-Jung; Nussinov, Ruth (2000-03-01). "Factors enhancing protein thermostability". Protein Engineering, Design and Selection 13 (3): 179-191. doi:10.1093/protein/13.3.179. ISSN 1741-0126.

56. Sokalingam, Sriram; Raghunathan, Govindan; Soundrarajan, Nagasundarapandian; Lee, Sun-Gu (2012-07-09). "A Study on the Effect of Surface Lysine to Arginine Mutagenesis on Protein Stability and Structure Using Green Fluorescent Protein". PLOS ONE 7 (7): e40410. doi:10.1371/journal.pone.0040410. ISSN 1932-6203.
57. Dambacher, S; Hahn, M; Schotta, G (2010/07). "Epigenetic regulation of development by histone lysine methylation". Heredity 105 (1): 24-37. doi:10.1038/hdy.2010.49. ISSN 1365-2540.

58. Martin, Cyrus; Zhang, Yi (2005/11). "The diverse functions of histone lysine methylation". Nature Reviews Molecular Cell Biology 6 (11): 838-849. doi:10.1038/nrm1761. ISSN 1471-0080.

59. Black, Joshua C.; Rechem, Capucine Van; Whetstine, Johnathan R.. "Histone Lysine Methylation Dynamics: Establishment, Regulation, and Biological Impact". Molecular Cell 48(4): 491-507. doi:10.1016/j.molcel.2012.11.006

60. Choudhary, Chunaram; Kumar, Chanchal; Gnad, Florian; Nielsen, Michael L.; Rehman, Michael; Walther, Tobias C.; Olsen, Jesper V.; Mann, Matthias (2009-08-14). "Lysine Acetylation Targets Protein Complexes and CoRegulates Major Cellular Functions". Science 325 (5942): 834-840. doi:10.1126/science.1175371. ISSN 0036-8075. PMID 19608861.

61. Shiio, Yuzuru; Eisenman, Robert N. (2003-11-11). "Histone sumoylation is associated with transcriptional repression". Proceedings of the National Academy of Sciences 100 (23): 13225-13230. doi:10.1073/pnas.1735528100.

62. Wang, Hengbin; Wang, Liangjun; Erdjument-Bromage, Hediye; Vidal, Miguel; Tempst, Paul; Jones, Richard S.; Zhang, Yi (2004/10). "Role of histone H2A ubiquitination in Polycomb silencing". Nature 431 (7010): 873878. doi:10.1038/nature02985. ISSN 1476-4687.

63. Shoulders, Matthew D.; Raines, Ronald T. (2009). "Collagen structure and stability". Annual Review of Biochemistry 78: 929-958. doi:10.1146/annurev.biochem.77.032207.120833. ISSN 1545-4509. PMID 19344236. PMC PMC2846778.

64. Civitelli, R.; Villareal, D. T.; Agnusdei, D.; Nardi, P.; Avioli, L. V.; Gennari, C. (November 1992). "Dietary L-lysine and calcium metabolism in humans". Nutrition (Burbank, Los Angeles County, Calif.) 8 (6): 400-405. ISSN 08999007. PMID 1486246.

65. Vaz, Frédéric M.; Wanders, Ronald J. A. (2002-02-01). "Carnitine biosynthesis in mammals". Biochemical Journal 361 (3): 417-429. doi:10.1042/bj3610417. ISSN 0264-6021. PMID 11802770.

66. Yamauchi, Mitsuo; Sricholpech, Marnisa (2012-05-25). "Lysine posttranslational modifications of collagen". Essays In Biochemistry 52: 113133. doi:10.1042/bse0520113. ISSN 0071-1365. PMID 22708567.

67. Vollmer, Waldemar; Blanot, Didier; Pedro, De; A, Miguel (2008-03-01). "Peptidoglycan structure and architecture". FEMS Microbiology Reviews 32 (2): 149-167. doi:10.1111/j.1574-6976.2007.00094.x. ISSN 0168-6445.

68. Curtiss, R. (May 1978). "Biological containment and cloning vector transmissibility". The Journal of Infectious Diseases 137 (5): 668-675. ISSN 0022-1899. PMID 351084.

69. Flanagan, Judith L.; Simmons, Peter A.; Vehige, Joseph; Willcox, Mark DP; Garrett, Qian (2010-04-16). "Role of carnitine in disease". Nutrition \& Metabolism 7: 30. doi:10.1186/1743-7075-7-30. ISSN 1743-7075.

70. Chromiak, Joseph A; Antonio, Jose. "Use of amino acids as growth hormone-releasing agents by athletes". Nutrition 18 (7-8): 657-661. doi:10.1016/s0899-9007(02)00807-9.

71. Corpas, E.; Blackman, M. R.; Roberson, R.; Scholfield, D.; Harman, S. M. (July 1993). "Oral arginine-lysine does not increase growth hormone or insulin-like growth factor-I in old men". Journal of Gerontology 48 (4): M128-133. ISSN 0022-1422. PMID 8315224.

72. Griffith, Richard S.; Walsh, David E.; Myrmel, Kurt H.; Thompson, Ronald W.; Behforooz, Ali (1987). "Success of L-Lysine Therapy in Frequently Recurrent Herpes simplex Infection". Dermatology 175 (4): 183-190. doi:10.1159/000248823. ISSN 1018-8665.

73. Thein, D.J.; Hurt, W.C.. "Lysine as a prophylactic agent in the treatment of recurrent herpes simplex labialis". Oral Surgery, Oral Medicine, Oral Pathology 58 (6): 659-666. doi:10.1016/0030-4220(84)90030-6.

74. Chi, Ching-Chi; Wang, Shu-Hui; Delamere, Finola M.; Wojnarowska, Fenella; Peters, Mathilde C.; Kanjirath, Preetha P. (2015-08-07). "Interventions for prevention of herpes simplex labialis (cold sores on the lips)". The Cochrane Database of Systematic Reviews (8): CD010095. doi:10.1002/14651858.CD010095.pub2. ISSN 1469-493X. PMID 26252373.

75. DiGiovanna, John J. (1984-01-01). "Failure of Lysine in Frequently Recurrent Herpes Simplex Infection". Archives of Dermatology 120 (1). doi:10.1001/archderm.1984.01650370054010. ISSN 0003-987X.

76. Milman, N.; Scheibel, J.; Jessen, O. (1980). "Lysine prophylaxis in recurrent herpes simplex labialis: a double-blind, controlled crossover study". Acta Dermato-Venereologica 60 (1): 85-87. ISSN 0001-5555. PMID 6153847.

77. Pinnell, S. R.; Krane, S. M.; Kenzora, J. E.; Glimcher, M. J. (1972-05-11). "A heritable disorder of connective tissue. Hydroxylysine-deficient collagen disease". The New England Journal of Medicine 286 (19): 1013-1020. doi:10.1056/NEJM197205112861901. ISSN 0028-4793. PMID 5016372.

78. Rudman, Daniel; Sewell, Charles W.; Ansley, Joseph D. (1977-09-01). "Deficiency of Carnitine in Cachectic Cirrhotic Patients". Journal of Clinical Investigation 60 (3): 716-723. doi:10.1172/jci108824. ISSN 0021-9738. 
79. Rushton, D. H. (July 2002). "Nutritional factors and hair loss". Clinical and Experimental Dermatology 27 (5): 396-404. ISSN 0307-6938. PMID 12190640.

80. Emery, P W (2005/10). "Metabolic changes in malnutrition". Eye 19 (10): 1029-1034. doi:10.1038/sj.eye.6701959. ISSN 1476-5454.

81. Ghosh, Shibani; Smriga, Miro; Vuvor, Frederick; Suri, Devika; Mohammed, Husein; Armah, Seth Mensah; Scrimshaw, Nevin S (2010-10-01). "Effect of lysine supplementation on health and morbidity in subjects belonging to poor peri-urban households in Accra, Ghana". The American Journal of Clinical Nutrition 92 (4): 928-939. doi:10.3945/ajen.2009.28834. ISSN 0002-9165.

82. Houten, Sander M.; te Brinke, Heleen; Denis, Simone; Ruiter, Jos PN; Knegt, Alida C.; de Klerk, Johannis BC; Augoustides-Savvopoulou, Persephone; Häberle, Johannes et al. (2013-04-09). "Genetic basis of hyperlysinemia". Orphanet Journal of Rare Diseases 8: 57. doi:10.1186/1750-1172-8-57. ISSN 1750-1172.

83. Hoffmann, Georg F.; Kölker, Stefan (2016). Inborn Metabolic Diseases. Springer, Berlin, Heidelberg. pp. 333-348. doi:10.1007/978-3-662-497715_22. ISBN 9783662497692.

84. Dancis, J.; Hutzler, J.; Ampola, M. G.; Shih, V. E.; van Gelderen, H. H.; Kirby, L. T.; Woody, N. C. (May 1983). "The prognosis of hyperlysinemia: an interim report". American Journal of Human Genetics 35 (3): 438-442. ISSN 0002-9297. PMID 6407303. PMC PMC1685659.

85. Mills, Philippa B; Struys, Eduard; Jakobs, Cornelis; Plecko, Barbara; Baxter, Peter; Baumgartner, Matthias; Willemsen, Michèl A A P; Omran, Heymut et al. (2006/03). "Mutations in antiquitin in individuals with pyridoxinedependent seizures". Nature Medicine 12 (3): 307-309. doi:10.1038/nm1366. ISSN 1546-170X.

86. Mills, Philippa B.; Footitt, Emma J.; Mills, Kevin A.; Tuschl, Karin; Aylett, Sarah; Varadkar, Sophia; Hemingway, Cheryl; Marlow, Neil et al. (2010-0701). "Genotypic and phenotypic spectrum of pyridoxine-dependent epilepsy (ALDH7A1 deficiency)". Brain 133 (7): 2148-2159. doi:10.1093/brain/awq143. ISSN 0006-8950.

87. Hagen, Jacob; Brinke, Heleen te; Wanders, Ronald J. A.; Knegt, Alida C.; Oussoren, Esmee; Hoogeboom, A. Jeannette M.; Ruijter, George J. G.; Becker, Daniel et al. (2015-09-01). "Genetic basis of alpha-aminoadipic and alpha-ketoadipic aciduria". Journal of Inherited Metabolic Disease 38 (5): 873-879. doi:10.1007/s10545-015-9841-9. ISSN 0141-8955.

88. Hedlund, Gary L.; Longo, Nicola; Pasquali, Marzia (2006-05-15). "Glutaric acidemia type 1". American Journal of Medical Genetics. Part C, Seminars in Medical Genetics 142C (2): 86-94. doi:10.1002/ajmg.c.30088. ISSN 15524868. PMID 16602100. PMC PMC2556991 